\title{
Heat Resistant Ni-Cr-Fe Steels for Superplastic Forming Dies: From Material Microstructure to Die Design
}

\author{
Gerard BERNHART ${ }^{1, a}$, Vincent VELAY ${ }^{1, b}$, Philippe LOURS ${ }^{1, c}$ \\ ${ }^{1}$ Université de Toulouse; INSA, UPS, Mines Albi, ISAE; ICA (Institut Clément Ader), \\ F-81013 Albi cedex 09 France \\ ${ }^{1}$ Ecole des Mines Albi, Centre CROMeP, Campus Jarlard, F-81013 Albi cedex 09 France \\ agerard.bernhart@mines-albi.fr, 'bincent.velay@mines-albi.fr, ${ }^{c}$ philippe lours@mines-albi.fr
}

Keywords: SuperPlastic Forming Die, Heat Resistant Steel, Microstructure, Mechanical Properties, Design and Simulation

\begin{abstract}
.
During superplastic forming, dies are subjected to high temperatures and severe environmental conditions. Optimum material grade choice and die design have to take into account all these combined parameters. Microstructure evolution and high temperature mechanical properties are investigated and reported for various Heat Resistant Cast Steels. New die concepts are suggested for energy and cost savings.
\end{abstract}

\section{Introduction}

Historically, research and development in superplasticity and SPF technology did not progress jointly as focus was mainly placed on the development of new advanced superplastic materials more than on the optimisation of the practical aspects of SPF industrialisation [1,2].

Concerning dies, various grades of Heat Resistant Cast Steels, especially if service temperature exceeds $700^{\circ} \mathrm{C}$, have been developed and are now available. These were mainly derived form CRES (Corrosion REsistant Steels) grades used in petrochemical and metallurgical industry. Over the years a careful alloy composition selection was performed by die manufacturers, in order to propose an optimal compromise between manufacturing, performance and cost [3].

The main driving force for SPF die composition selection are, first, the severe in service conditions with temperatures up to $950^{\circ} \mathrm{C}$ and long term exposure requiring oxidation and structural stability, whereas thermal cycling during successive sheet removals and forming periods require high thermo-mechanical fatigue and creep/relaxation resistance [4]. Castability in relation with die design, machinability and weldability before and after service, as well as alloying element cost are the second most important factors.

Novodays alloy composition is mainly based on Iron and a relevant carbon content to promote hardening carbides precipitation for high temperature properties. Chromium content is close to $25 \%$ in order to give high temperature oxidation resistance to the steel. At this stage the steel has a ferritic microstructure with a relatively low thermal expansion coefficient. In order to prevent sigma phase embrittlement, nickel is added and the matrix structure becomes austenitic, the amount being related to the requested application: $50 \%$ for heating platens, forming cover plates and containers, or close to $40 \%$ for molds due to the better machinability of this grades. Tungsten and Niobium are added in small quantities (between 1 to 4\%) to control carbide distribution and increase high temperature mechanical properties. For special high temperature applications (heating platens), 15\% cobalt can be substituted to nickel.

Over the last years, five material grades with almost constant chromium content (i.e. close to $20 \%$ to $25 \%$ for oxidation resistance) have been investigated. In these grades, nickel content varies 
from $1 \%$ resulting in a ferritic structure up to $50 \%$ for which the structure is austenitic. Various topics have been addressed, amongst them : macro, meso and microstructure, material high temperature aging and oxidation, high temperature creep/relaxation and fatigue, weld repair procedures, material constitutive modeling and die simulation and optimization. A huge amount of results have been derived from more than 1500 test samples.

This paper aims to give an overview of the major results obtained on some of these topics, at the Research Centre on Tools, Materials and Processes, during the last 12 years in the frame of several $\mathrm{PhD}$ works performed in close relation with industrial partners.

\section{Material Multi-scale Microstructure and Aging Evolution}

Dies made of Heat Resistant Cast Steels (HRCS) are produced by sand casting and can be as heavy as 20 tons. Whatever the composition is, a dual macro-structure is generated during solidification as can be seen in Fig. 1. Near the surface a columnar structure (coarse primary dendritic arms) promoted by the high thermal gradient established during cooling, grows normal to the surface. It reaches a mean length of $50 \mathrm{~mm}$. Then, as the thermal equilibrium is reached an equiaxed structure develops. These equiaxed grains have a size ranging between 5 to $10 \mathrm{~mm}$. It has been shown by EBSD that each of them has a unique grain orientation [5]. If die wall thickness is low only the columnar structure develops. At higher magnification, the secondary dendrite arms are visible with a typical size of 100 to $300 \mu \mathrm{m}$ separated by carbide rich primary interdentritic zones; their general meso-structure is similar whatever the location (columnar or equiaxed) even if their size somewhat varies (in relation either to the position in the billet (Fig 1) or in relation to the alloy composition). The typical microstructural grain is visible at the highest magnification of Fig 1.

The MC type primary carbides are essentially chromium carbides but other carbides have been identified depending on the grades i. e. W-carbides for the $50 \% \mathrm{Ni}$ and $\mathrm{Nb}-\mathrm{Mo}$ carbides for the $40 \%$ Nickel grades. Fig 2 shows a typical grain of a 50\% Nickel HRCS. Within the dendritic grains, fine dispersed secondary $\mathrm{M}_{23} \mathrm{C}_{6}$ (here $\mathrm{M}=\mathrm{Cr}$ but they can be $\mathrm{Nb}$ or $\mathrm{W}$ or $\mathrm{Ti}$ depending on grades) carbides are visible. They have precipitated during the stabilization treatment carried out at temperatures close to $950^{\circ} \mathrm{C}$ after casting and TEM observations have revealed a facetted structure (Fig 2). A secondary carbides depleted zone is also observed near the primary carbide network.

Test ingots have been aged in industrial presses for more than 4 months, where they followed a typical industrial cycle. Samples observed after such long term aging have shown no major microstructure evolution. Only a slight evolution in the distribution and size of secondary chromium carbides $\left(\mathrm{M}_{23} \mathrm{C}_{6}\right)$ precipitated in the austenitic matrix was observed [6]. This stability was also confirmed by uniaxial tensile properties and impact strength energy measured on as-received and aged materials according to various isothermal and cyclic long term exposures.

\section{Mechanical Properties}

\section{High temperature mechanical properties}

For all grades, high temperature mechanical tensile tests have been performed on specimens machined parallel to the outer surface. The gage of the specimens is $12 \mathrm{~mm}$ diameter and $45 \mathrm{~mm}$ long, so as to take into account the coarse microstructure of the material. All mechanical tests are performed on an experimental testing facility composed of a servo-hydraulic fatigue equipment with water cooled round specimen hydraulic wedges, an air cooled high temperature extensometer and a $6 \mathrm{~kW}$ induction heating coil.

Tensile test results of a $35 \% \mathrm{Ni}$ HRCS are shown in Fig 4 for temperatures ranging from $20^{\circ} \mathrm{C}$ to $950^{\circ} \mathrm{C}$. The specific testing procedure conducted at a constant strain rate of $\dot{\varepsilon}=10^{-3} \mathrm{~s}^{-1}$ includes also a relaxation step at $\varepsilon=1,5 \%$ for 300 seconds. Whatever the grade is, for temperatures lower than $600^{\circ} \mathrm{C}$, the HRCS material is highly brittle, with low strains to rupture and no evidence of 
relaxation. Rupture is mainly intergranular along the interdendritic primary carbides [7]. At higher temperatures, the material becomes ductile and an important stress relaxation is observed when subject to a constant strain. Moreover, no significant difference was observed for the samples extracted form the columnar or the equiaxed zones of the test billets, despite the apparent morphological difference [7]. This confirms that the relevant microstructural feature controlling the mechanical properties are the secondary arm grains.

Fig 7 reports the rupture stresses obtained for four grades containing increasing Ni content. Amongst them only the ferritic grade $(0,5 \% \mathrm{Ni})$ behaves differently as the brittleness is enhanced. At high temperatures the higher is the nickel content the higher are the mechanical properties. Nevertheless as material undergoes viscous flow at high temperature, these values are strain rate dependent, i.e. the higher the strain rate the higher the stress reported [8,9]. As a consequence the strain rate has to be carefully considered when comparing properties reported in various supplier data sheets. Typical stress-strain curves obtained for a 40\% Ni HRCS are compared in Fig 8 for seven different temperatures and confirm the rapid change in behavior for temperatures lower than $650^{\circ} \mathrm{C}$.

\section{Mechanical properties at grain size level}

During the testing campaigns, it was observed that elastic modulus measured with a $12 \mathrm{~mm}$ long gage length extensometer shows big discrepancies between samples coming from a same lot, i.e. values at room temperature vary between $160 \mathrm{GPa}$ to $230 \mathrm{GPa}$ [5]. It was suspected that these differences may be related to the size of the primary arm structure that are close to the gage length.

In order to investigate this particular behavior, a Digital Image Correlation technique was applied at the grain level. As it can be seen in Fig 7 (left) a flat shaped sample was etched in order to reveal the primary grains and the primary carbides. A CCD camera with a focusing lens was used to capture the whole width of the sample $(16 \mathrm{~mm})$. The primary carbides are used as those random marks required for DIC technique application. During testing, images were taken at successive times, and the DIC Software VIC3D ${ }^{\mathrm{TM}}$ is used for local displacement measurement and local strain calculations.

Fig 7 (right) shows the measured tensile strain field at a given time of the tensile test. It is obvious that the strains are homogeneous in each primary arm grain structure as expected from the crystal orientation measurements, but there is an important heterogeneity from one grain to another, inducing important strain discontinuities between the grains. Local elasticity modulus have been measured along two parallel lines drawn on the sample (Fig 7 right), the circle giving a approximate size that is used for such a local measurement (note that the radius has been changed from one position to the other in order to remain in the local grains). Results are reported in Fig 8 where the difference between the local values and the value given by the $12 \mathrm{~mm}$ gage length extensometer is plotted. Differences of $50 \%$ have been measured and confirm that these materials have an important local strain mismatch corresponding to the primary dendride arm grains. Such strain heterogeneities may promote initiation of interdentrictic cracks, especially at low temperatures where material exhibits low ductility.

\section{Oxidation and oxide spallation}

Numerous long term investigations have been performed with respect to oxidation behavior at high temperature as it might be a damaging environmental parameter, in exposing samples in furnaces and measuring their weight gain (oxidation) or loss (spallation) at increasing times. Fig 9 shows that the oxidation kinetic of the $50 \% \mathrm{Ni}$ HRCS is parabolic, whatever the testing temperature is. Nevertheless a rapid increase in oxidation appears between $900^{\circ} \mathrm{C}$ and $950^{\circ} \mathrm{C}$. A similar behavior was observed for all the tested grades as they have all a similar $\mathrm{Cr}$ content $(\sim 25 \%)$ and shows that oxidation is controlled by the diffusion of $\mathrm{Cr}$. 
Thermo-mechanical loading also affects the oxide thermally grown on the surface of dies. Repeated cooling and final return to room temperature provoke the occurrence of compressive stresses within the scale. Depending on the thermal behaviour of the metallic substrate and its ability to relieve those stresses, the scales may fracture and detach from the base material in the shape of individual spalls thereby affecting the quality of the surface. From this point of view, ferritic heat resistant cast steels due to lower expansion coefficient and lower creep resistance, prove to be more suitable than austenitic alloys $[10,11]$.

A quantification of this process was introduced with the spallation kinetic curve (Fig 10). It consists of the measurement of the mass of the oxide that has spalled from the sample upon return to room temperature. For short time exposure, oxide scale is thin and no spall is observed: spallation curve follows oxidation curve. For longer exposures, spalling initiates and for very long durations the sample losses mass as a depletion of $\mathrm{Cr}$ appears at sample surface. Spallation is enhanced when the exposure time and correlatively the oxide thickness increase thereby degrading the surface of the tool material to be in contact with the SPF sheets

\section{Optimal die design and production}

If die material performances are major drivers for a grade selection with respect to the industrial requirements, new environmental constrains are applied to the Superplastic Forming (SPF) industry that may impact the today state of the art. As a matter of fact SPF is an energy consuming process in which massive dies have to be produced and then to be heated for long times at high temperatures.

Regarding these issues the hollow die concept (Fig 11) proposed recently [3] seems to be an interesting alternative. The objective is to take advantage of the high forming temperature and the high radiative thermal transfer at these temperatures to decrease the mass of the dies. If thermal environment of industrial press furnaces have been identified [12], if die material elasto-viscoplastic behavior model have been identified and implemented in FEM codes $[5,8,9]$ and if the a representative modeling of the die cycle has been constructed $[12,13,14]$, then the gains of such solutions can be evaluated.

A first attempt was done on the die for which Fig 12 corresponds to a local section. The thermal boundary conditions used in the optimization process are presented in the figure, either only conductive on the bottom or mixed (conductive and radiative). The conclusion drawn after this study shows that there is an interest to investigate such a way, as a matter of fact gains have been identified at the die production level and at the die user's level.

In the die manufacturing, the alloy quantity can be decreased by a factor of 2 (including risers and runners) and cooling by a factor of 4 to 6 . As a consequence a decrease of segregation risks, a quality improvement and a decrease of die cost and lead time are expected. Benefits in use are a decrease of mass for in shop handling, a decrease of the cycle heating time of $30 \%$ and a decrease of the thermo-mechanical stresses due to the decrease of the thermal gradient $(20 \%)$. As a consequence the hollow die concept may be a route towards a first step of green SPF die concept.

\section{Conclusion}

Heat resistant cast steels show complex macro, meso and microstructures that are mainly not composition dependent. On the other hand the macroscopic properties, if they are not microstructure dependent, rely on the alloy composition that generates primary and secondary carbide structures. HRCS are highly brittle at low temperature and their use in dies requires caution when heating and especially cooling where thermal gradients may induce high tensile stresses. Many experimental results have been obtained over the years on various grades, and they are now available to deal with the complex industrial environment that is equipment and process dependent. Nevertheless, important advances have been achieved in thermal and thermo-mechanical simulation of dies, that 
allow now the implementation of die design and die optimization. Amongst these the hollow die concept seems to be a good candidate with respect to environmental constrains

\section{References}

[1] D.G. Sanders : Mat. Sci. Forum, 304-306, 805-812, (1999)

[2] N. Chandra : Mat. Sci. Forum, 243-245, 643-652. (1997)

[3] P. Barnet, J-Y Moraux : EuroSPF08, France (2008) [hal-00371031 - version 1]

[4] P. Lours, S. Baleix, G. Bernhart : THERMEC 2000, 4-8 dec, 2000, Las Vegas, USA

[5] A. Martinier : PdD thesis, (2006), Mines Nationale Supérieure des Mines de Paris

[6] P. Lours, T. Cutard, G. Bernhart, C. Levaillant : Int. Journal of Materials and Products and Technology, SPM1, 2, (2001), 445

[7] S. Baleix, P. Lours, G. Bernhart : in proceedings of the 8th International Conference on Mechanical Behaviours of Materials. Victoria (Canada) Vol 2, 653-657, (1999)

[8] G. Bernhart, A. Martinier, V. Velay and J-Y Moraux : ICSAM 2009 Conference, 30 june -02 july 2009, Seattle

[9] A.A. Deshpande, S.B. Leen, T.H. Hyde.: in EuroSPF 2008, France (2008) [hal00337989 - version 1]

[10] S. Baleix, G. Bernhart, P. Lours : Materials Science and Engineering A, Vol 372, n², (2002), p $155-166$

[11] S. Baleix, S. Le Roux, G. Bernhart, P. Lours : Journal of Material Processing Technology, Vol 118/1-3, (2001), p 322-329

[12] V. Velay, T. Cutard, N. Guegan: EuroSPF08, France (2008) [hal-00348613 - version 1]

[13] C.Y. Gao, P. Lours, G. Bernhart : International Journal of Processing Technology, vol 169, (2005) p 281-291

[14] J., Shang, T.H. Hyde, S.B. Leen : Journal of Strain Analysis, vol 41, no 8, 2006, pp 539-559.

[15]T. Branza, F. Deshaux-Beaume, V. Velay, P. Lours : Journal of materials Processing Technology, Vol 209, № 2, (2009) pp 944-953 


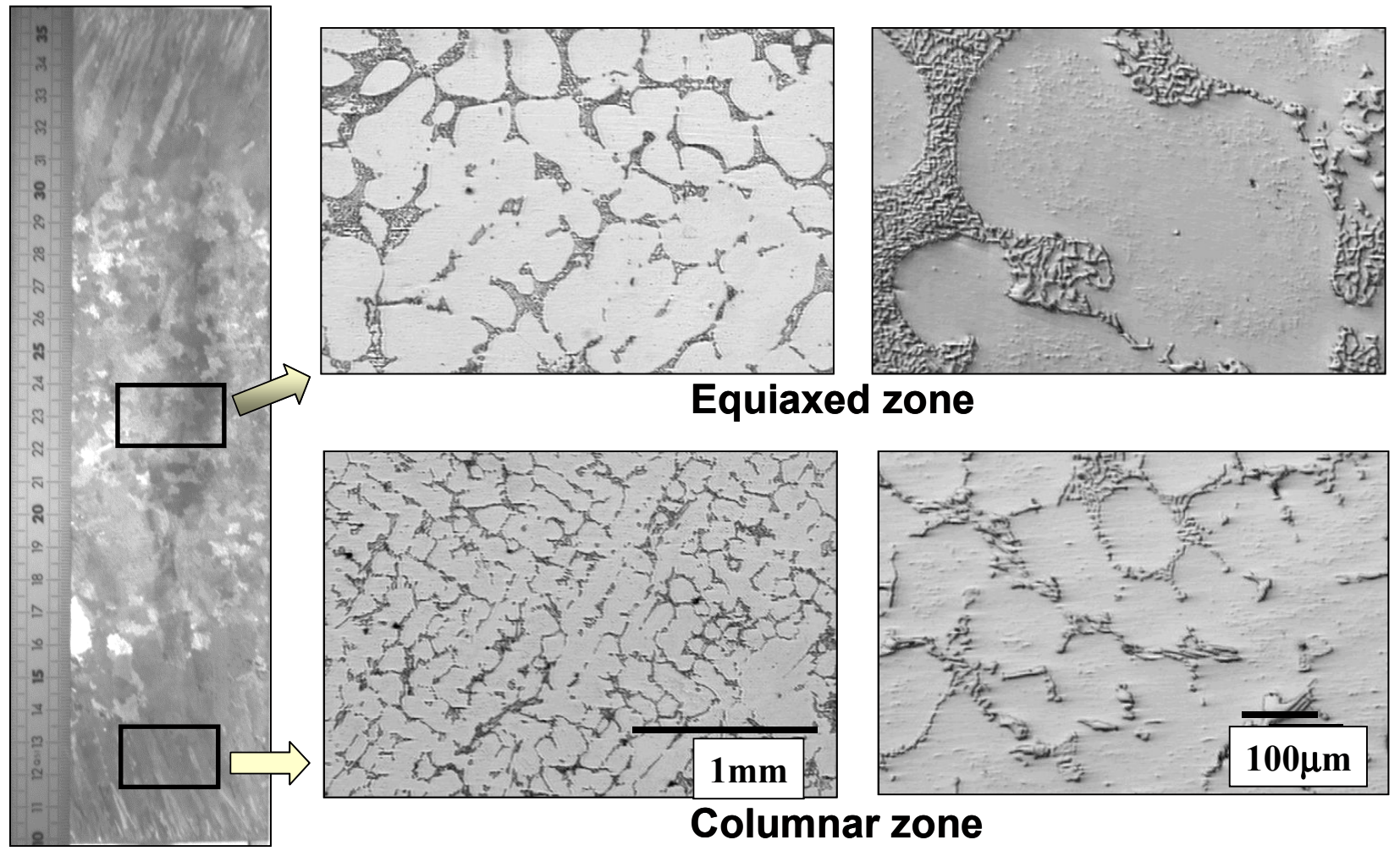

Fig. 1: Microstructure of columnar and equiaxed zone at various magnifications
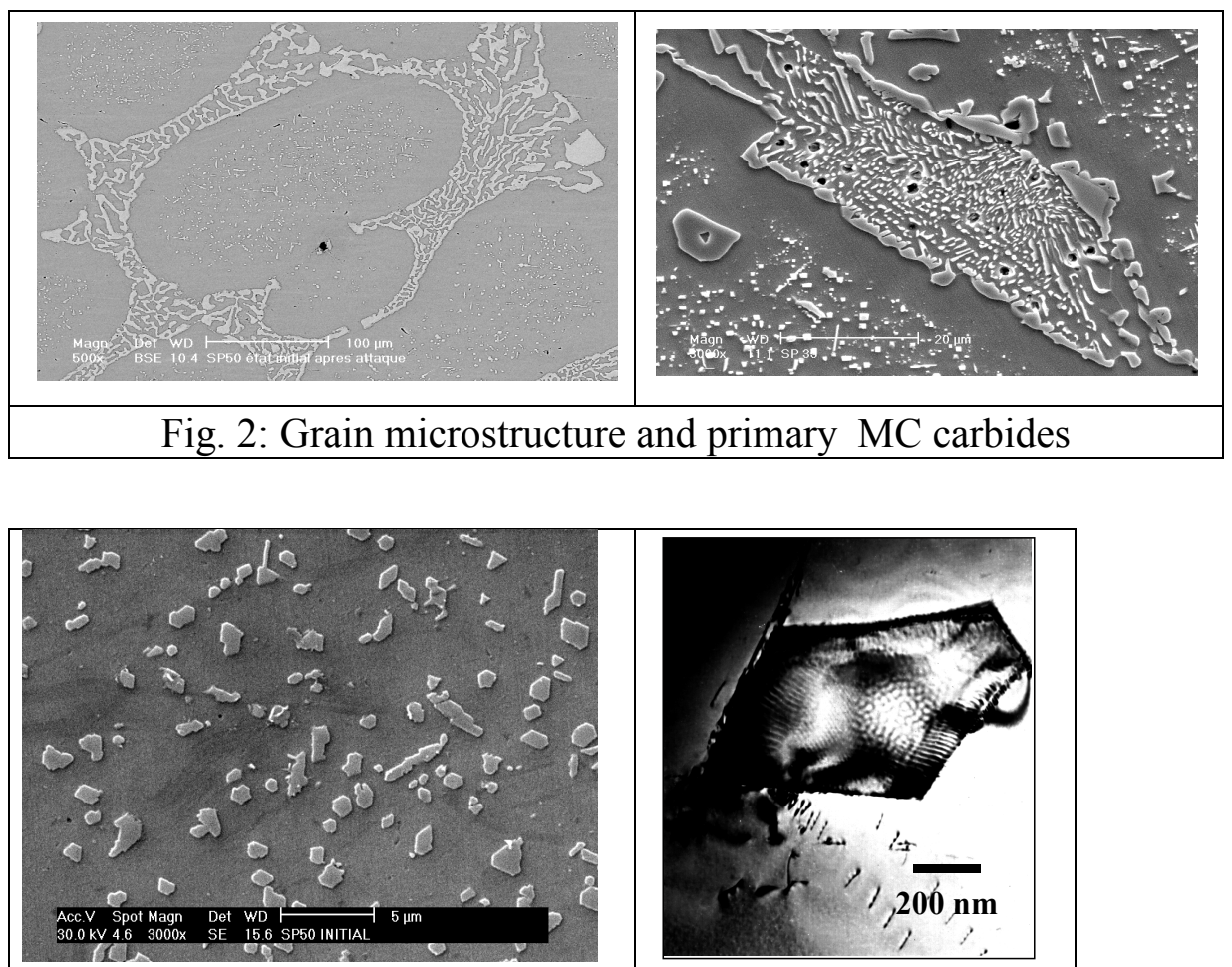

Fig. 3: Secondary $\mathrm{M}_{23} \mathrm{C}_{6}$ carbides (SEM and TEM) 

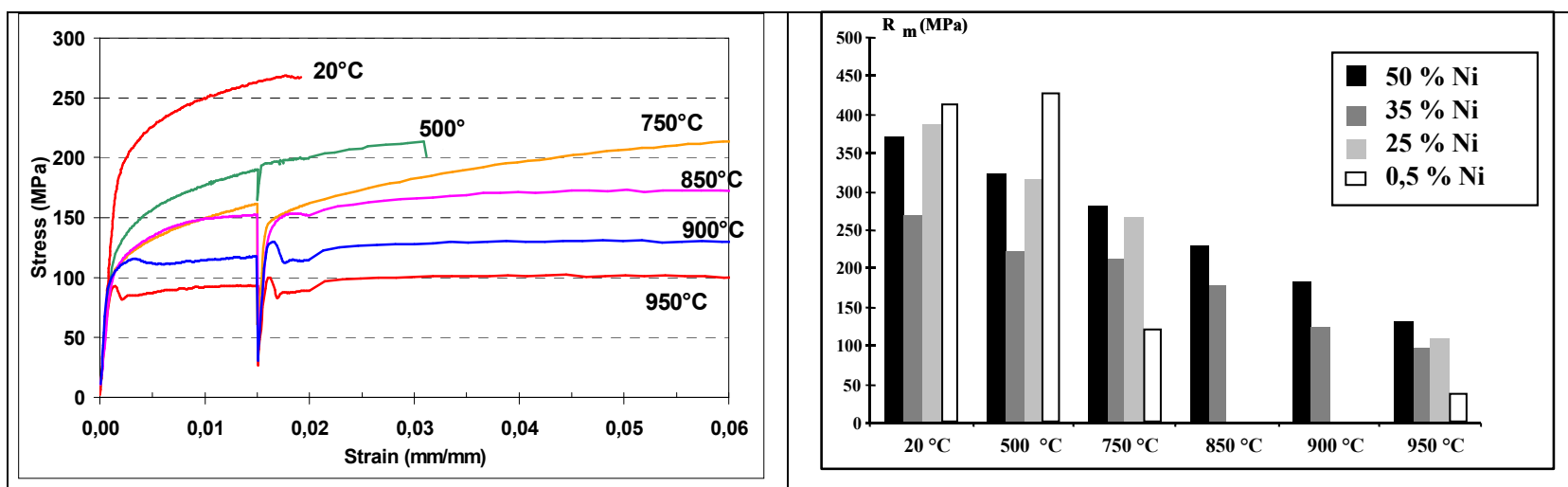

Fig. 4: Tensile testing with relaxation (columnar Fig. $5:$ Rupture stress with respect to Ni content zone, $\dot{\varepsilon}=10^{-3} s^{-1}, 50 \%$ Nickel) and temperature (columnar zone, $\dot{\varepsilon}=10^{-3} s^{-1}$ )

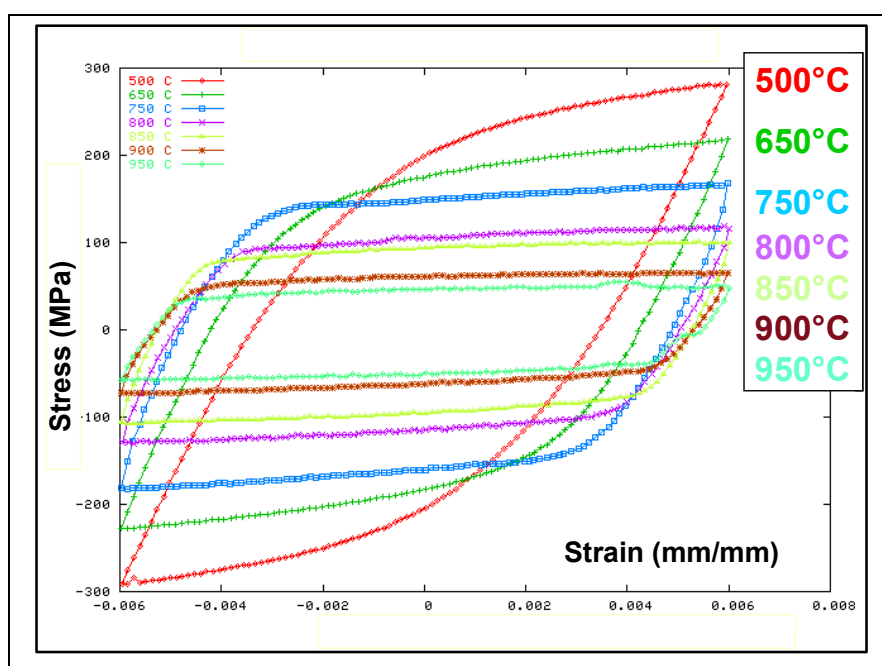

Fig. 6: Stress-strain fatigue loops for increasing temperature $\left(\dot{\varepsilon}=10^{-3} s^{-1}\right)$
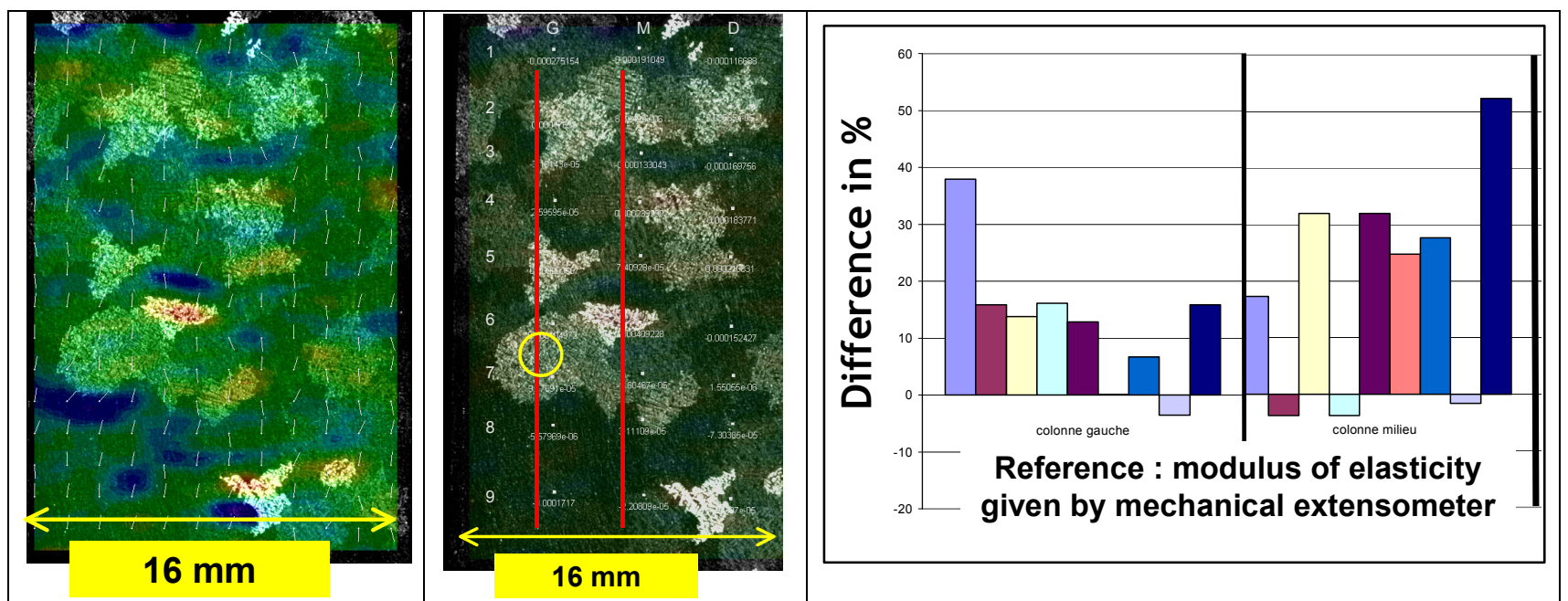

Fig. 7: Strains at the grain size level (Digital Image Correlation on carbides)

Fig. 8: Local strain versus extensometer strain 

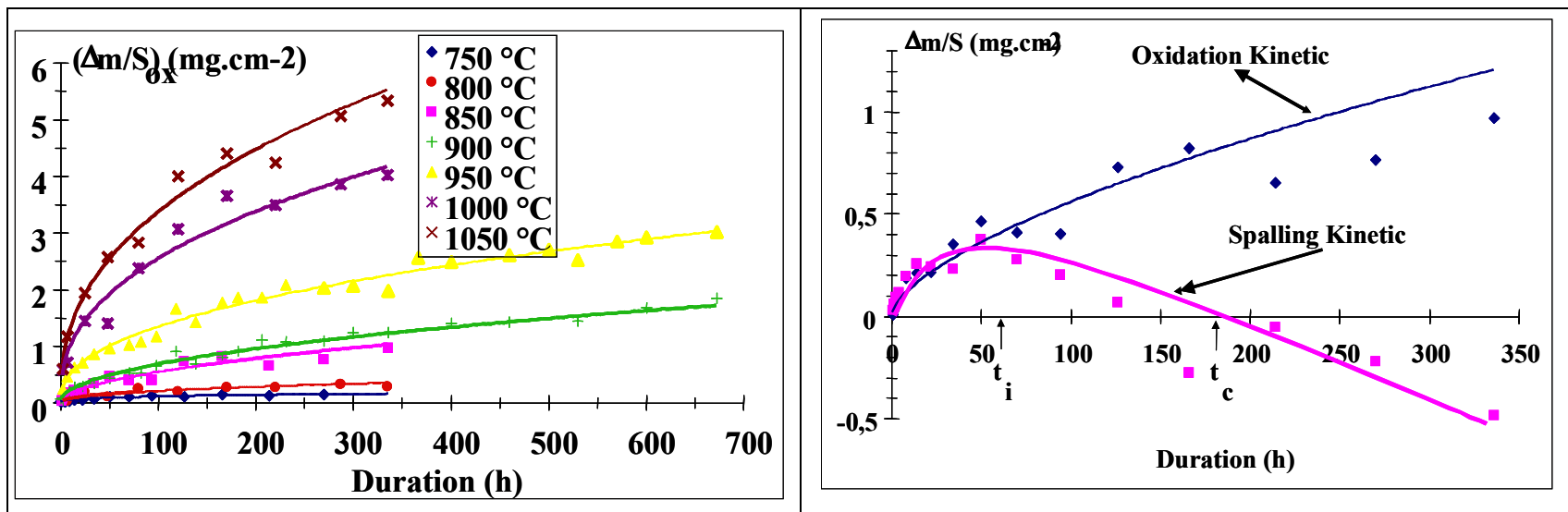

Fig. 9 : Oxidation kinetics of $50 \%$ Ni HR Steel

Fig. 10 : Spallation kinetic of $50 \%$ HR Steel
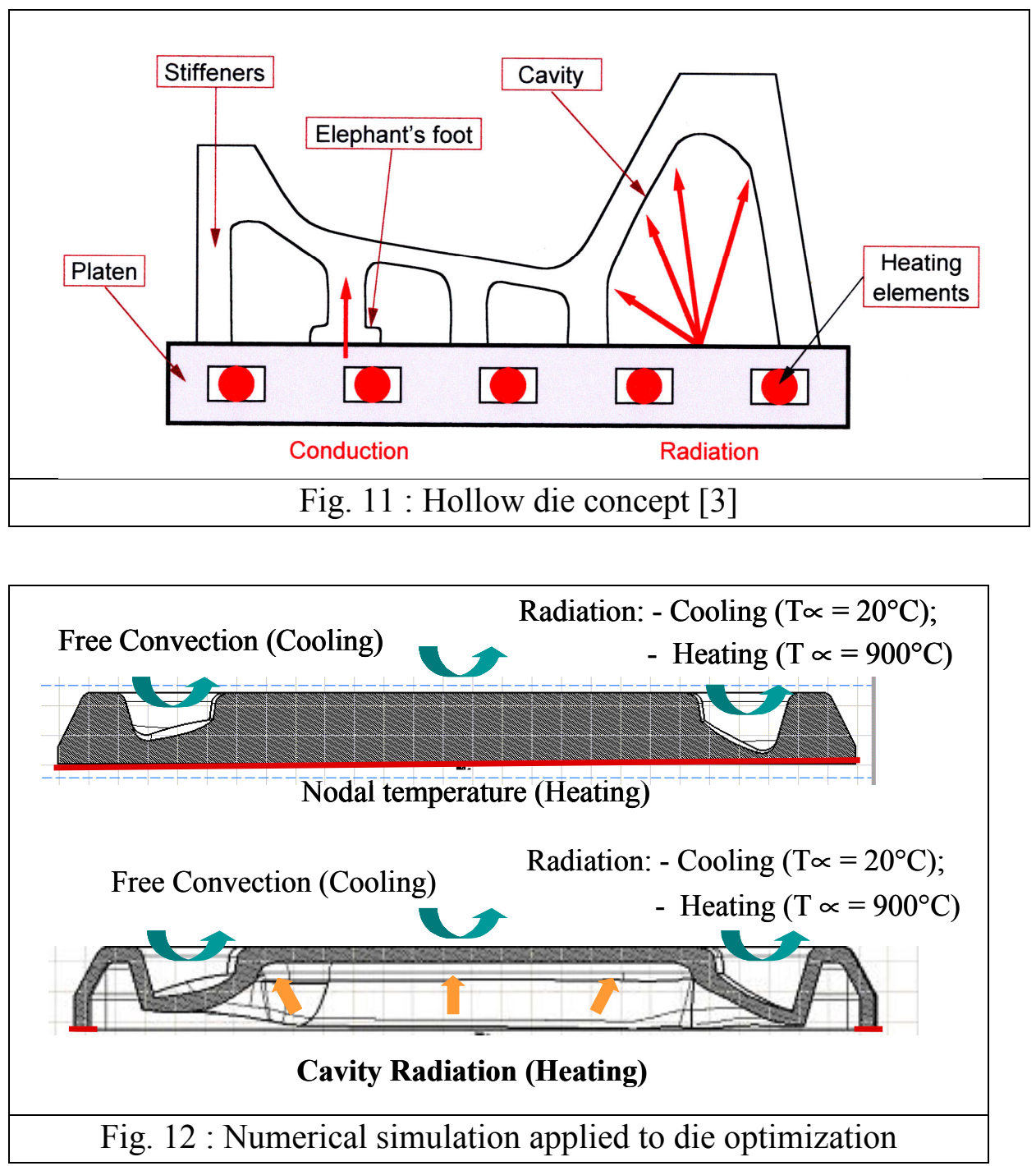